Cilt: 2

Sayı: 1

Sayfa: $41-48$

Mayıs 2013

\section{Minimum çakışan yersel lazer taramalarının birleştirmesi için fotogrametrik özellikler}

\section{Sibel Canaz ${ }^{1,2, *}$ Ayman Habib ${ }^{1}$}

\author{
${ }^{1}$ Geomatik Mühendisliği Bölümü, Calgary Üniversitesi, Schulich School of Engineering, Calgary, AB, Kanada \\ ${ }^{2}$ Harita Mühendiliği Bölümü, Karadeniz Teknik Üniversitesi, Trabzon, Türkiye \\ Özet
}

Günümüzde, insan yapımı binaların 3 Boyutlu (3B) modellemesine olan ilgi ve talep veri toplama sistemlerindeki gelişmeler ve büyüyen potansiyel uygulama aralığ ile birlikte arttı. Mevcut durumda, $3 B$ veriler iki teknoloji ile sağlanmaktadır: fotogrametri ve lazer taraması. Lazer taramalarının toplanması ve islenmesinde zaman kaybı söz konusudur. Bütün bir 3B model elde etmek için birçok lazer taraması gerekmektedir. Her bir lazer taraması ayrı koordinat sistemlerinde olduğu için; $3 B$ modeller ancak bu farklı koordinatlardaki lazer tamamlarının bir araya dizilmesi ile mümkündür. Bu dizilim "birleştirme" olarak bilinir. Birçok birleştirme teknikleri doğru 3B model için toplanan lazer taramaları arasında büyük oranda çakışma ister. Bu araştırmanın temel amacı fotogrametrik veri kullanarak lazer taramaları arasındaki büyük oranda istenilen çakışmadan kaçınmaktır. Birleştirme tekniklerinde genellikle noktalar kullanarak lazer taramaları arasındaki ilişki bulunur. Bu önerilen araştırmada düzlemsel ve doğrusal özellikler çıkarılmış ve kullanılmıştır. Son olarak, nitel ve nicel kalite kontrol yöntemleri önerilen birleştirme metodu sonucunu analiz etmek için yapılmıştır.

Anahtar Sözcükler

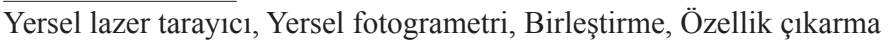

\section{Abstract \\ Photogrammetric features for the registration of terrestrial laser scans with minimum overlap}

Volume: 2

Issue: 1

The interest and demand for 3 Dimensional (3D) documentation of man-made structures have increased with the continuous improvement in data acquisition systems and the expanding range of potential applications. Currently, 3D data can be obtained through two technologies: photogrammetry and laser scanning. In spite of the proven quality of static laser scanning, the collection and processing of laser scans is a time consuming process and the derivation of complete $3 D$ models requires multiple scans with each scan having its own coordinate system. Therefore, the different scans should be aligned in a common coordinate system. This alignment process is known as "registration". Current registration techniques require large overlap area between the collected scans in order to obtain reliable estimation of the transformation parameters relating these scans. The main objective of this research is to avoid the requirement of large overlap areas among the laser scans using photogrammetric data for the registration process. Registration methods generally use points as primitives to relate the different laser scans. In this research, photogrammetric linear and planar features are used for the proposed registration method. Finally, qualitative and quantitative quality control measures are proposed for analyzing the result of the proposed registration method.

Keywords

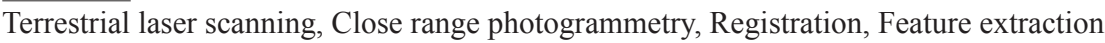

\footnotetext{
** Hakemli değerlendirme sürecinden geçerek, Jeodezi ve Jeoinformasyon Dergisi'nde yayına kabul edilen ve asıl yazı dili İngilizce olan "Photogrammetric features for the registration of terrestrial laser scans with minimum overlap " başlıklı eserin Türkçe diline çevirisidir. Çeviren; Volkan Yılmaz

* Sorumlu Yazar: Tel: +90 4623772776 Fax: +90 4623280918

E-posta: sibelcanaz@gmail.com (Canaz S.), ahabib@ucalgary.ca (Habib A.), volkanyilmaz.jdz@gmail.com (Yılmaz V.)
} 


\section{Giriş}

Bir nesnenin dijital ortamda temsil edilmesi 3D modelleme olarak ifade edilmektedir. İnsan yapısı olan yapıların 3D modellemesi dijital belgeleme açısından gereklidir, belgelemeden ise çeşitli uygulamalarda faydalanılmaktadır. Örneğin, eğer tarihi binalar doğal veya insan kaynaklı olaylar sonucunda zarar görmüşlerse bu yapıların 3D modellemeleri yeniden inşa edilmelerinde faydalı olabilir. Arkeolojik alanların/objelerin 3D modellerinin incelenmesi bir diğer 3D modelleme örneği olarak verilebilir. Mimarlık, ormancilık, jeoloji, şehir planlama ve inşaat mühendisliği 3D modellemeyi sıklıkla kullanan bazı alanlardır. 3D modellemeye dayalı çok geniş uygulama alanları olması nedeniyle, çoğu araştırmacı genel anlamda çevremizin ve özellikle de insan yapısı nesnelerin 3D modellerinin üretilmesine odaklanmaktadırlar.

Lazer tarama teknolojisi doğrudan 3D verilerin elde edilebilmesi nedeniyle 3D modellerin oluşturulması için kullanılan standart bir teknik olmuştur. İlgili objelerin 3D modellerinin üretilmesini sağlayan daha geleneksel bir yaklaşım ise fotogrametrik yeniden model oluşturma yaklaşımıdır. Lazer taramanın aksine, 3D veriler iki görüntüde de ortak özelliklerin belirlendiği ve karşı1ıklı konumsal ışınların kesişiminim matematiksel olarak tanımlandığı belli bir oranda üst üste binen görüntülerden elde edilebilir. Lazer tarama ve fotogrametrik sistem özellikleri dikkate alındığında, kullanıcılar taranmış yüzeylerin koordinatlarının doğrudan üretildiği lazer tarama tekniğiyle 3D model üretimi yöntemiyle ilgilenmektedir. Oysa birçok uygulamada tek bir Yersel Lazer Tarayıcı (TLS) ile bir yapının tamamını taramak imkânsızdır. $\mathrm{Bu}$ nedenle ölçülen yüzeyin tamamının taranabilmesi için farklı noktalardan birkaç TLS taraması yapmak gerekmektedir (yani, farklı noktalardan gerçekleştirilen farklı taramalar söz konusu objenin alt modellerinin üretilmesini sağlar). Elde edilen taramalar/alt modeller farklı noktalardaki lazer tarama birimleri ile bağlantılı olan koordinat sistemleri ile ilişkilidir. Anlamlı 3D modeller elde etmek için toplanan tarama verilerinin ortak bir koordinat sisteminde olması ön koşuldur. Bu ortak koordinat sistemi tanımlanması aşaması referanslama olarak bilinir.

Etkin bir referanslama dikkatlice elde edilmesi gereken dört bileşenden oluşur: uygun kontrol noktası seçimi, dönüşüm parametreleri, benzerlik ölçümü ve eşleme stratejisi (Al-Ruzouq 2004). Öncelikle birbiriyle çakışan modellerden güvenilir bir şekilde belirlenebilen/üretilebilen referanslama için kontrol detayları elde edilmelidir. TLS taramalarının referanslanması için kullanılan ortak detaylar nokta, çizgi veya düzlemsel (alansal) özellikler olabilir. TLS nokta bulutunun düzensiz dağılımından dolayı farklı TLS taramalarındaki eşlenik noktaların belirlenmesi neredeyse imkânsızdır. Diğer bir yandan, TLS taramalarındaki düzlemsel ve doğrusal özelliklerin tanımlanabilmesi mümkündür (Habib vd. 2008). $\mathrm{Bu}$ nedenle bu çalışmadan düzlemsel ve doğrusal özellikler referanslama ortak detayları olarak belirlenmiştir. Referanslamanın ikinci aşaması ilgili veri setlerinin referans sistemleri arasındaki ilişkileri tanımlayan dönüşüm parametrelerinin belirlenmesidir (yani, ilgili objenin farklı kısımlarını kapsayan alt modeller). Alt modellerin koordinat sistemleri arasındaki ilişkiyi tanımlamak için genellikle üç öteleme, üç dönüklük ve bir ölçek faktörü kullanılır. Referanslamanın üçüncü bileşeni olan benzerlik ölçüsü referanslama aşamasından sonra ilgili ortak özelliklerin çakışmasını matematiksel olarak tanımlamak için üst üste binen taramalardaki eşleşmiş özelliklerle dönüşüm parametrelerini ilişkilendirir (Renaduin vd. 2011). Son olarak, referanslama probleminin çözümü için genel bir şema olarak kabul edilen eşleştirme stratejisi, elde edilen benzerlik ölçüsü kullanılarak gerekli olan dönüşüm parametrelerinin tahmini için ortak özelliklerin değiştirilmesi amaciyla dizayn edilmelidir (Al-Ruzouq 2004).

Literatürde birçok farklı referanslama tekniği bulunmaktadır. Farklı TLS taramalarının çakışan alanlarındaki noktalar arası mesafenin minimize edilmesine dayanan İteratif En Yakın Nokta (ICP) 3D nokta bulutlarının referanslaması için en popüler ve sıklıkla kullanılan algoritmadır (Besl ve McKay 1992). Temel olarak ICP referanslama tekniğinde iki veri setinin en yakın noktaları arasındaki Öklid mesafesinin karesinin toplamı minimize edilir. ICP referanslama tekniğine benzer olarak Chen ve Medioni (1992) TLS taramalarının çakışan alanlarında nokta-düzlem normali mesafelerinin minimize edildiği bir yöntem geliştirmişlerdir. Bu yöntemlerin bir başka çeşidi olan ICPP (Iterative Closest Projected Point) hem noktadan noktaya hem de noktadan düzleme referanslama tekniği olarak düşünülebilir (Al-Durgham vd. 2011). ICPP yöntemi bir taramadaki bir nokta ile bu noktanın diğer taramadaki en yakın üç noktaya izdüşümü arasındaki mesafeyi minimize eder. Diğer bazı araştırmacılar referanslandırma amacıyla fotogrametrik veri ile TLS taramalarını entegre etmek için TLS sisteminin üstüne monte edilen (hibrit sistem) bir kamera kullanmışlardır. Toplanan görüntüler monte işlemi esnasında iki sistem arasinda elde edilen parametreleri kullanarak TLS taramalarını referanslamak için kullanılmıştır. Bu dönüklük ve kayıklık gibi parametreler önceden yapılan bir sistem kalibrasyon işlemi ile belirlenmiștir. Dold ve Brenner (2006) hibrit bir sistem kullanarak referanslama yapmışlardır. Al-Manasir ve Fraser (2006) hibrit bir sistem kullanarak referanslama için başka bir örnek ortaya koymuşlardır. TLS taramalarını otomatik olarak referanslamak için obje üzerinde kodlanmış hedefler kullanılmıștır. Referanslama amaçlı olarak hibrit sistemin kullanılmasının temel dezavantajı TLS tarama verilerinin ve fotogrametrik verilerin aynı zamanda toplanmas1 için uygun bir gözlem noktasının her zaman bulunamamasıdır. Tarama verileri elde edilirken TLS taramaları ve referans koordinat sistemi arasındaki ilişkinin belirlenmesi için Global Konum Belirleme (GPS) alıcısı da kullanılabilir. Örneğin Balzani vd. (2002) jeo-referanslandırma taramaları için GPS alıcısı kullanmışlardır. Bu yöntemin dezavantajı minimum bindirmeli taramaların jeo-referanslandırılması için kullanılan kontrol noktalarının GPS kullanılarak toplanmasının görüntü verisinin elde edilmesinden daha zahmetli oluşudur. ICP ve diğer birçok referanslama tekniği genellikle farklı alt modelleri ilişkilendirirken dönüşüm parametrelerinin güvenilir olarak belirlenmesi için TLS taramalarının büyük oranda bindirilmesini gerektirir. Bu çalışmada büyük oranda bindirme gerekliliği nispeten daha kısa zamanda elde edilebilen fotogrametrik veriler kullanılarak yok edilmiştir/ azaltılmıştır. Doğrusal ve düzlemsel özellikler fotogrametrik verilerden kolayca elde edilebildiğinden dolayı, fotogrametrik modeldeki ve TLS taramalarındaki tanımlanmış doğrusal 
ve düzlemsel özellikler farklı taramaların ortak bir referans koordinat sistemine dönüştürülmesi için kullanılır.

Sonuç olarak, önerilen referanslama yönteminin pek çok avantajı vardır. TLS taramalarında minimum bindirme alanlarının bulunmasının ve 3D model elde etmek için fotogrametrik verilerin kullanılmasının temel avantajı arazideki veri toplama zamanının azaltılmasıdır, bu sayede veriyi elde etme maliyeti de azalacaktır. Ayrıca, veri toplama aşamasındaki bazı kısıtlamaların var olduğu durumlarda (örneğin, yoğun trafik, dağınık çevre ve/veya stabil olmayan zemin gibi) söz konusu objeyi taramak için daha az sayıda tarama gerekebilecektir. Bir diğer yandan, minimum zamanda ve çalışma alanının stabilite gereksinimleri olmaksızın oldukça hızlı görüntü elde edilebilir. Ayrıca, önerilen yöntem toplanan veri miktarını azaltmaktadır, böylece veri işleme ve düzenleme faaliyetlerine pozitif yönde katkı sağlamaktadır. Bu bağlamda, yersel lazer tarayıcılar ile elde edilen fazla miktarda veri ileriki veri işleme faaliyetlerinde karışıklığa ve depolama ihtiyacında artışa neden olabileceği unutulmamalıdır. Buna ek olarak, görüntü verisi olmadan bu taramaların referanslanması için bindirme bölgelerindeki eğim/yön değişiminin yanı sıra taramalarda önemli miktarda bindirme olmalıdır. Bazı durumlarda bu muhtemel olmayabilir. Örneğin, bindirme bölgelerinde uygun geometriye sahip olmayan büyük bir yapı varsa (bindirme bölgesi kaliteli bir referanslama için iyi bir geometri göstermeyebilir - dış cephesi büyük olan bir bina gibi). Böyle durumlarda, önerilen yöntem fotogrametrik modelde tanımlanabilen minimum iki tane paralel olmayan doğrusal özellik bulunduğu müddetçe taramaları referanslamayı mümkün kılacaktır. Önerilen yöntemin bir diğer avantajı da farklı algılayıcılardan elde edilen verilerin ortak bir platformda referanslanmasının sağlamasıdır. Bu şekilde referanslamanın temel faydalarından bir tanesi görüntülerin spektral bilgilerinin lazer tarama ile elde edilen nokta bulutuyla ilişkilendirilebilmesidir. Bunun yanında, minimum bindirmeli yersel tarama verileri hava araçları ile üretilen lazer tarama verileri veya hava fotoğrafları ile (bu veriler TLS tarama verilerinde de bulunan ortak bazı özellikleri içermeli) aynı koordinat sistemine dönüştürülebilir. Sonuç olarak, yoğun eşleştirme teknikleri ile bindirmeli görüntüler kullanmaya artan ilgiyle beraber görüntülerden yoğun nokta bulutu üretebilmek bir gerçekliktir. Önerilen yöntem lazer ve görüntü tabanlı nokta bulutlarının referanslanmasına olanak sağlamaktadır. Bu referanslama yoğun eşleştirme algoritmaları ve sonuçları ile beraber lazer tarama sistemlerinin kalibrasyonuna pozitif katkı yapmaktadır.

Referanslama aşamasını takiben elde edilen dönüşüm parametrelerinin kalitesini doğrulamak amacıyla bir kontrol metodu izlenmiştir. Referanslanmış taramaları çizerek ve görsel olarak denetleyerek nitel bir kalite kontrolü gerçekleştirilmiştir. Diğer yandan, referanslanmış yüzeyler arasindaki nokta-düzlem normali mesafeleri hesaplanarak nicel bir kalite kontrolü yapılmıştır. Önerilen referanslama yönteminin sonuçları ile ICPP yönteminin sonuçları kıyaslanarak diğer bir nicel kalite kontrolü gerçekleştirilmiştir. Bir sonraki bölüm fotogrametrik veri ve TLS taramalarından referanslama için gerekli kontrol detaylarının çıkartılmasını ele almaktadır. Ardından, referanslama ve kalite kontrol aşaması anlatılmıştır. Deneysel sonuçlar bölümü önerilen yöntemin performansını değerlendirmektedir. Son olarak sonuçlar ve gelecekteki çalışmalar için öneriler verilmiştir.

\section{TLS taramaları ve fotogrametrik verilerden özellik çıkarımı}

\subsection{Fotogrametrik verilerden özellik çıkarımı}

Bu çalışmada ilk olarak söz konusu objeyi kaplayan bindirmeli görüntüler çekilmiştir. Kamera kalibrasyonu ve görüntülerin elde edilmesinden sonra, demet dengeleme yöntemi kullanılarak keyfi tanımlanmış bir koordinat sisteminde bu görüntülerin konum ve dönüklüklerini belirlemek için bir dizi bağlantı noktaları tanımlanmıştır. TLS taramalarının aynı koordinat sisteminde tanımlanması için demet dengeleme işlemine ek bazı doğrusal ve düzlemsel özellikler katılmıştır. Bu özellikler daha sonra TLS taramalarında belirtilecektir. Sınır boyunca bazı noktalar yardımıyla düzlemsel bir yüzey tanımlanmıştır. Daha detaylı söylemek gerekirse, çoklu görüntülerde üç veya dört nokta gözlenmiştir ve model uzay koordinatları demet dengeleme işlemiyle belirlenmiştir. Diğer yandan, doğrusal özellikler uç noktaları ile temsil edilmiştir. Uç noktalarının koordinatları demet dengelemesine de ilave edilebilen eşdüzlemsellik sınırlamasından türetilmiştir (Habib vd. 2004; Habib vd. 2007; Renaudin vd. 2011). Uç noktaları görüntülerin sadece bir tanesinde, bir dizi ara nokta ise bindirmeli görüntülerde sadece tek resim değerlendirmesi ile tanımlanır ve eşdüzlemsellik sınırlamasında kullanılır. Doğrusal özelliklerin fotogrametrik verilerden türetilmesi konusu ile ilgilenen okuyucular detaylı bilgi için Habib vd. (2004), Habib vd. (2007) ve Renaudin vd. (2011) kaynaklarını inceleyebilir. Özet olarak, doğrusal ve düzlemsel özellikleri temsil eden bir dizi nokta fotogrametrik demet dengelemesi ile türetilmiştir. Bu noktalar bu çalışmada Fotogrametrik Olarak Yeniden Oluşturulmuş Veri (PRD) olarak gösterilmiştir. Referanslama için PRD noktaları TLS taramalarından elde edilen özelliklerle birlikte kullanılmıştır.

\subsection{Yersel lazer taramalarından özellik çıkarımı}

TLS taramalarından özellik çıkarımı aşamasında aynı düzleme ait olan noktaları belirlemek için bir segmentasyon işleminden faydalanılmıştır. Bu çalışmada Lari vd. (2011) tarafindan tanitılan parametre tabanlı yeni bir segmentasyon yaklaşımı kullanılmıştır. Bu yöntemde her bir noktanın komşuluğu uyarlanabilir bir silindir kullanılarak oluşturulmuştur. Bu silindirin ekseni söz konusu noktayı barındıran yerel düzleme dik olan doğru ile çakışacak şekilde yönünü değiştirmektedir. Bu uyarlanabilir silindir söz konusu noktanın özniteliklerini çıkartmak için kullanılır ve bu öznitelikler bir birikimli dizinde depolanır. Birikimli dizinin düzenlenmesi için mozaikleme kullanmak yerine bir kd-veri yapısı nokta bulutunun niteliklerini depolamak için kullanılır. Son olarak, benzer niteliklerin kümelerini belirlemek amaciyla bir tepe noktası tespiti işleminden faydalanılır (Lari ve Habib 2012). Düzlemsel bölgelerin belirlenmesinden sonra fotogrametrik verilerde tanımlanan düzlemlerin her birinden üç veya dört nokta elle seçilir. TLS taramalarında seçilen noktalar aynı düzlemsel yapıyı tanımlamak için fotogrametrik veride seçilen noktalar ile eşlenik olmayabilir. Doğrusal özellik çıkarımı için komşu düzlemler kesiştirilir. Bu şekildeki düzlem kesişimleri sınırsız sayıda doğrusal özellik çıkarımına olanak verir. Sonsuz doğrusal özellik ile düzlem kesişimleri etrafında oluşturulan bir tampon bölgede bulunan komşu 
düzlemlerdeki nokta bulutunun izdüşümü vasıtasıyla TLS doğrusal özellik uç noktaları oluşturulur (Al-Durgham 2007). Düzlemsel özelliklere benzer şekilde TLS verisindeki ve fotogrametrik verideki doğruları belirleyen noktaların eşlenik olması gerekmemektedir. Karşılıklı doğrusal ve düzlemsel yüzeylerdeki eşlenik olmayan noktalar referanslama aşamasında kullanılır. Bu aşamada doğrusal ve düzlemsel özelliklerin çıkarımını içeren fotogrametrik model üretiminin görüntülerin elle işlenmesine dayandığı dikkate alınmalıdır. Otomatik üçgenleme ve doğrusal özelliklerin çıkarımı bu ve bundan sonraki çalışmaların odak noktası olacaktır. Bununla birlikte, doğrusal ve düzlemsel özellikler otomatik olarak TLS verisinden çıkarılır. Görüntüdeki ve TLS verisindeki doğrusal özelliklerin eşleştirilmesi birtakım manuel işlemlere dayanmaktadir.

Bir TLS verisinden otomatik olarak çıkarılan doğrusal ve düzlemsel özellikler ve fotogrametrik veriden elle çıkarılan özelliklere ait örnekler Şekil 1.’ de gösterilmiştir.

\section{Benzerlik ölçümü ve kalite kontrolü}

Fotogrametrik olarak yeniden oluşturulmuş veri (PRD), TLS taramaları ve yer koordinat sistemi arasındaki dönüşüm parametrelerinin belirlenmesi için bir benzerlik ölçümü kullanılır. Düzlemsel ve doğrusal özellikler noktalar ile temsil edildiğinden dolayı, PRD, TLS taramaları ve zemin koordinat sistemindeki eşlenik özelliklerin ilişkilendirilmesi için nokta tabanlı bir 3D benzerlik dönüşümü seçilir (Eşitlik 1). Bir 3D benzerlik dönüşümü veri ile referans koordinat sistemini ilişkilendiren dönüşüm parametreleriyle (üç öteleme, üç dönüklük ve bir ölçek faktörü vb.) uyumludur. TLS verileri arasında ölçek farklılıkları olmaması ve ölçeğin ölçülen mesafelerden doğru olarak belirlenmesine rağmen, görüntülerden 3D model üretimi aşamasında rastgele bir ölçek kullanılmasından dolayı fotogrametrik model ölçeğinin TLS verisine uyması için bu çalışmada ölçek kullanılmıştır.

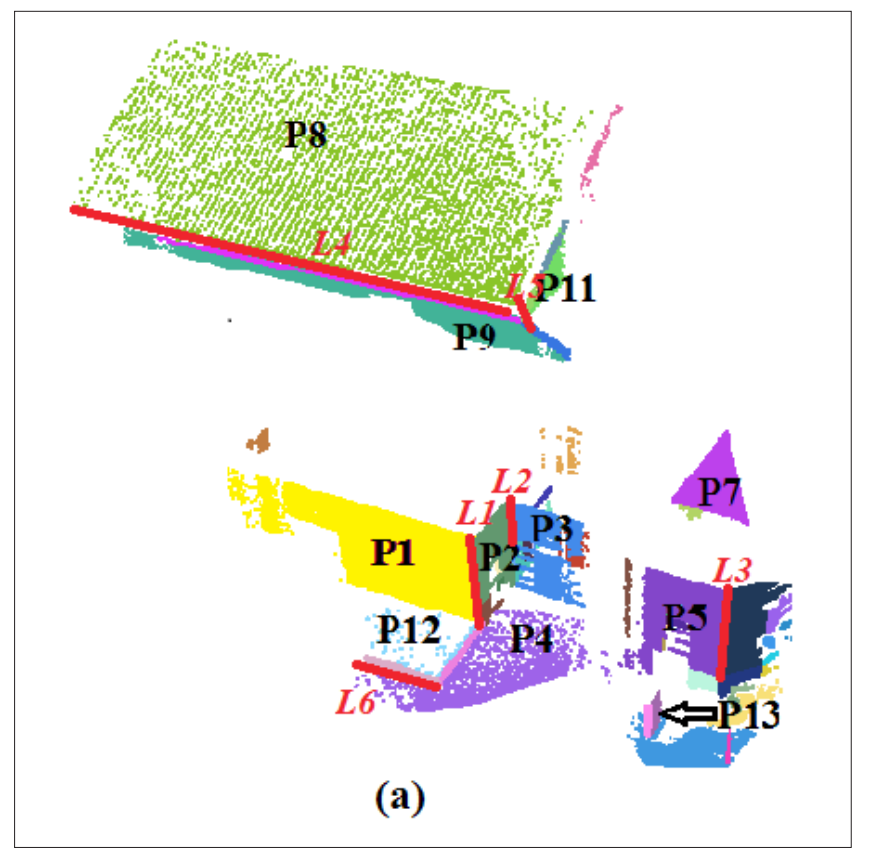

$\vec{X}_{\text {Scan }_{i} / P R D}=\vec{X}_{T_{\text {scan }_{i} / P R D}}+S_{\text {scan }_{i} / P R D} R_{\text {Scan }_{i} / P R D} \vec{X}_{G}$

burada:

- $\operatorname{Scan}_{i}$ i. TLS taramasını;

$-\overrightarrow{\mathrm{X}}_{\text {scan }_{i}} /$ PRD) $=\left[\begin{array}{l}X_{\text {Scan }_{i} / P R D} \\ Y_{\text {scan }_{i} / P R D} \\ Z_{\text {Scan }_{i} / P R D}\end{array}\right] \begin{aligned} & \begin{array}{l}\text { Fotogrametrik olarak yeniden } \\ \text { oluşturulan verideki veya }\end{array} \\ & \text { taramasindaki nokta koordinat- } \\ & \text { larının gözlem vektörlerini; }\end{aligned}$

$-\overrightarrow{\mathrm{X}}_{\left.\mathrm{T} \operatorname{scan}_{i} / P R D\right)}=\left[\begin{array}{l}X_{T_{\text {scan }_{i} / P R D}} \\ Y_{T_{\text {scan }_{i} / P R D}} \\ Z_{T_{\text {scan }_{i} / P R D}}\end{array}\right] \begin{aligned} & i \text {.TLS taraması ve fotogrametrik } \\ & \text { olarak yeniden oluşturulmuş veri } \\ & \text { veya yer koordinat sistemi arasında- } \\ & \text { ki öteleme vektörünü }\end{aligned}$

- $\mathrm{R}_{\text {SCan }_{i}} / P R D_{i}$ TLS taraması ve fotogrametrik olarak yeniden oluşturulmuş veri veya yer koordinat sistemi arasındaki ölçek faktörünü

$\left.-\mathrm{R}_{\mathrm{scan} i} / P R D\right)=\left[\begin{array}{lll|l}i \text {.TLS taramasi veya foto- } \\ r_{11} & r_{12} & r_{13} \\ r_{21} & r_{22} & r_{23} & \begin{array}{l}\text { grametrik olarak yeniden } \\ \text { oluşurulmuş veri ve yer koor- } \\ \text { dinat sistemi arasındaki } \Omega, \Phi,\end{array} \\ r_{31} & r_{32} & r_{33}\end{array} \begin{array}{l}\text { ve } K \text { ile tanımlanan dönüklük } \\ \text { matrisini, }\end{array}\right.$

- $\mathrm{X}_{\mathrm{G}}=\left[\begin{array}{c}X_{G} \\ Y_{G} \\ Z_{G}\end{array}\right]$ İlgili noktanın obje uzayındaki yer koordinatlarını gös-

Daha önce bahsedildiği üzere fotogrametrik modeldeki ve TLS taramalarındaki karşılıklı özellikleri temsil eden noktaların eşlenik olması gerekmemektedir. Bu nedenle, geleneksel En küçük kareler dengeleme işlemi gözlem denklemleri ile ilgili hata vektörünün ağırlıklarını değiştirerek güncellenir (Eşitlik 1). Ağırlıkların değiştirilmesinin kavramsal temeli, karşılıklı doğrusal veya düzlemsel özellikler boyunca eşlenik olmayan noktalar arasındaki mesafelerin minimize edilmesi yerine karşılıklı özellikler arasındaki normal mesafelerin minimize edilmesine dayanır. Modifikasyon işlemi doğrusal veya düzlemsel özellikleri çevreleyen noktalara ağırlık olarak sıfır verilmesiyle gerçekleştirilir. Bu

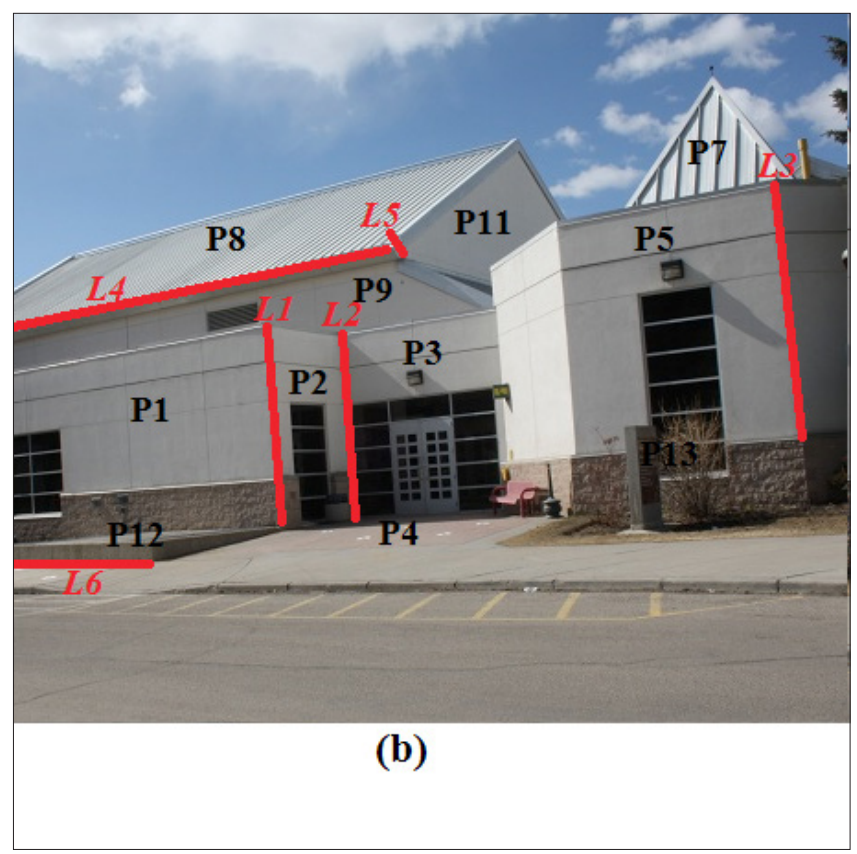


sayede, en küçük kareler yönteminde sadece doğrusal veya düzlemsel özelliklere dik yöndeki ağırlıklar dikkate alınır. $\mathrm{Bu}$ nedenle, fotogrametrik modeli ve farklı taramaları ilişkilendiren dönüşüm parametreleri alt modellerdeki eşlenik özellikler arasındaki normal mesafeleri en küçüğe indirgemek için hesaplanır. Ağırlık modifikasyon işlemleri ile ilgili daha detaylı bilgi Renaduin vd. (2011), Habib vd. (2011) ve Kersting (2012) kaynaklarından edinilebilir. Fotogrametrik özellikler tek bir referans koordinat sistemine (yani, demet dengelemesi için keyfi olarak seçilen referans sistem) referanslandığından dolayı referanslandırma işlemi dolaylı olarak farklı TLS taramalarını da tek bir model oluşturmak için çakıştırır ve ayrıca fotogrametrik modeli TLS verisi ile uyuşacak şekilde ölçekler. Daha sonra tüm model sağlanan kontrol noktaları yardımıyla yer koordinat sistemi ile ilişkilendirilir. Bu çalışmada TLS taramalarından birisi referans tarama olarak adlandırılmış ve ona ait referans koordinat sistemi aynı zamanda yer koordinat sistemi olarak seçilmiştir. $\mathrm{Bu}$ nedenle, en küçük kareler dengelemesi farklı taramaları ve fotogrametrik modeli referans taramadaki özellikler ile mümkün olduğunca uyuşana kadar aynı koordinat sisteminde birleştirir.

Önerilen metodun uygulanabilirliğini test etmek amacıyla referanslanmış taramalar nitel ve nicel olarak değerlendirilmiştir. Nitel kalite kontrolü için bütün TLS taramaları referans koordinat sistemine hesaplanan dönüşüm parametreleri kullanılarak ve birlikte çizimleri yapılarak dönüștürülmüştür. Ardından, referanslama işleminin kalitesi bindirmeli alanlardaki farklı taramalara ait nokta bulutlarının yakınlıkları kontrol edilerek görsel olarak değerlendirilmiştir. Buna ek olarak nicel kalite kontrolü iki yaklaşımla gerçekleştirilmiştir. Birincisinde, eşlenik düzlemsel bölgeler arasındaki nokta-düzlem normali mesafeleri değerlendirilmiș ve analiz edilmiştir. Nokta-düzlem normali mesafeleri PRD ve TLS taramaları arasındaki bindirmeli bölgeler için ve/veya eğer mevcutsa TLS taramaları arasındaki bindirmeli bölgeler için değerlendirilmiştir. İkinci nicel kalite kontrolü yaklaşımında elde edilen referanslama sonuçları ICP yaklaşımının bir türevi olan ICPP referanslama sonuçları ile kıyaslanmıştır. Şunu da söylemekte yarar vardır ki, ICPP referanslama işlemi farklı taramalar arasında geniş bindirme bölgeleri gerektirdiği için ek TLS taramaları kullanılmıştır. Bir sonraki bölüm deneysel sonuçlar ile ilgilidir. Burada, önerilen yöntemin kapasitesi ile referanslama kontrol detayları olarak düzlemsel ve doğrusal özelliklerin karşılaştırmalı performansları irdelenmektedir.

\section{Deneysel sonuçlar}

Önerilen referanslama yönteminin kapasitesini analiz etmek amacıyla gerçek deneysel veriler toplanmıştır ve referanslama yöntemlerinin sonuçları gösterilmiştir. Minimum bindirmeli dört TLS taraması Calgary Üniversitesi Rozsa Center'

Tablo 1: Düzlemsel özellik tabanlı referanslama yönteminin sonuçları

\begin{tabular}{|c|c|c|c|c|c|c|c|}
\hline & $\mathrm{XT}(\mathrm{m})$ & YT (m) & $\mathrm{ZT}(\mathrm{m})$ & Ölçek & $\Omega(\mathrm{o})$ & $\Phi(0)$ & $\mathrm{K}\left({ }^{\circ}\right)$ \\
\hline $\begin{array}{c}\text { TLS } \\
\text { taramal }\end{array}$ & 0 & 0 & 0 & 1 & 0 & 0 & 0 \\
\hline $\begin{array}{c}\text { TLS } \\
\text { tarama2 }\end{array}$ & $\begin{array}{c}-23.186 \\
( \pm 0.0287)\end{array}$ & $\begin{array}{c}-14.801 \\
( \pm 0.0219)\end{array}$ & $\begin{array}{c}-0.687 \\
( \pm 0.0805)\end{array}$ & 1 & $\begin{array}{c}0.234 \\
( \pm 0.1133)\end{array}$ & $\begin{array}{c}-0.429 \\
( \pm 0.2092)\end{array}$ & $\begin{array}{c}8.373 \\
( \pm 0.0484)\end{array}$ \\
\hline $\begin{array}{c}\text { TLS } \\
\text { tarama3 }\end{array}$ & $\begin{array}{c}69.677 \\
( \pm 0.0221)\end{array}$ & $\begin{array}{c}92.511 \\
( \pm 0.0293)\end{array}$ & $\begin{array}{c}1.335 \\
( \pm 0.0431)\end{array}$ & 1 & $\begin{array}{c}0.243 \\
( \pm 0.0624)\end{array}$ & $\begin{array}{c}0.313 \\
( \pm 0.0781)\end{array}$ & $\begin{array}{c}121.373 \\
( \pm 0.0441)\end{array}$ \\
\hline $\begin{array}{c}\text { TLS } \\
\text { tarama4 }\end{array}$ & $\begin{array}{c}-41.693 \\
( \pm 0.0298)\end{array}$ & $\begin{array}{c}91.370 \\
( \pm 0.0234)\end{array}$ & $\begin{array}{c}-0.251 \\
( \pm 0.0916)\end{array}$ & 1 & $\begin{array}{c}-0.291 \\
( \pm 0.1273) \\
(\end{array}$ & $\begin{array}{c}0.165 \\
( \pm 0.0769)\end{array}$ & $\begin{array}{l}-145.531 \\
( \pm 0.0447)\end{array}$ \\
\hline PRD & $\begin{array}{c}5.372 \\
( \pm 0.0184)\end{array}$ & $\begin{array}{c}1.610 \\
( \pm 0.0163)\end{array}$ & $\begin{array}{c}37.383 \\
( \pm 0.0143)\end{array}$ & $\begin{array}{c}0.998 \\
( \pm 0.000)\end{array}$ & $\begin{array}{c}30.584 \\
( \pm 0.2271)\end{array}$ & $\begin{array}{c}-74.546 \\
( \pm 0.0419)\end{array}$ & $\begin{array}{c}91.168 \\
( \pm 0.2261)\end{array}$ \\
\hline
\end{tabular}

da toplanmıștır. Taramalar toplanırken maksimum menzili ve açısal çözünürlüğü sırasıyla $200 \mathrm{~m}$ ve 32 mili radyan (veya 100 m' de $3 \mathrm{~mm}$ ) olan Trimble GS200 tarayıc1sı kullanılmıştır. Daha önce de belirtildiği gibi ICPP tabanlı referanslama yöntemi TLS taramaları arasında geniş bindirmeli alanlara ihtiyaç duymaktadır. Bu nedenle ICPP referanslama yaklaşımı için diğer minimum bindirmeli dört taramayla geniş oranda bindirmeye sahip iki ek TLS tarama verisi ve bir havadan lazer tarama verisi eklenmiştir. Fotogrametrik yeniden oluşturma için $0.00571 \mathrm{~mm}$ piksel boyutu olan Canon EOS Rebel XS kamerası kullanılarak Rozsa Center' in 16 adet görüntüsü çekilmiştir. Kamera $3888 \times 2592$ piksel boyutlarında görüntü üretmektedir ve $18 \mathrm{~mm}$ nominal odak uzaklığına sahiptir.

\subsection{Düzlemsel özellik tabanlı referanslama}

Bu deney için Rozsa Center'a ait 30 düzlemsel özellik TLS taramaları ve PRD' den çıkarılmıştır/türetilmiştir. Bu özellikler önerilen referanslama yönteminde kullanılmıştır ve sonuçları Tablo 1'de gösterilmiştir. Parantez içindeki değerler elde edilen parametrelerin standart sapmalarını göstermektedir. TLS tarama 1' in koordinat sistemi yer (referans) koordinat sistemi olarak kullanılmıştır.

\subsection{Doğrusal özellik tabanlı referanslama}

Bu deney için Rozsa Center' in 20 farklı doğrusal özelliği TLS taramaları ve PRD' den çıkarılmış ve önerilen referanslama yöntemi için kullanılmıştır. Elde edilen dönüşüm parametreleri standart sapmalarıyla beraber Tablo 2' de gösterilmiştir. Elde edilen parametreler ve standart sapmaları Tablo 1' deki sonuçlar ile kıyaslandığında doğrusal özelliklerin düzlemsel özellikler kadar referanslama kalitesi sağlamadığ varsayılabilir. Tablo 2' de görüldüğü üzere TLS 3 ve TLS 4 için düşey yer değiştirmelerin standart sapmaları ile TLS 2, TLS 3 ve TLS 4 için $\Omega$ ve $\Phi$ dönüklük açılarının standart sapmaları Tablo 1' ile kıyaslandığında oldukça yüksektir (Tablo 2' deki vurgulanan hücreler). Doğrusal özellik tabanlı referanslama yönteminin kalitesizliğinin nedenleri deneysel sonuçların kalite kontrolü bölümünde irdelenecektir.

\subsection{Kalite kontrolü ve önerilen düzlemsel ve doğrusal referanslama yöntemlerinin kıyaslanması}

Önerilen doğrusal ve düzlemsel özellik tabanlı referanslama yöntemlerinin kalite kontrolü ortak koordinat sistemine taşınmış taramaların nitel ve nicel denetimi ile gerçekleştirilmiştir. Nitel kalite kontrolü için referanslanmış TLS taramaları çizilmiş ve bindirme alanında görsel bir denetim yapılmıştır. Şekil 2' de her iki yöntemden elde edilen referanslanmış taramaların bir kısmı görülmektedir. Bu şekilde düzlemsel özellik tabanlı referanslamanın daha yüksek kalite gösterdiği (Şekil 2a) ve doğrusal özellik tabanlı referanslamanın farklı taramaların düşey yer değiştirmesinde hataya neden olduğu (Şekil 2b) açık

Tablo 2: Doğrusal özellik tabanlı referanslama yönteminin sonuçları

\begin{tabular}{|c|c|c|c|c|c|c|c|}
\hline & $\mathrm{XT}(\mathrm{m})$ & YT (m) & $\mathrm{ZT}(\mathrm{m})$ & Ölçek & $\Omega$ (o) & $\Phi(\mathrm{o})$ & $\mathrm{K}\left({ }^{\circ}\right)$ \\
\hline $\begin{array}{c}\text { TLS } \\
\text { taramal }\end{array}$ & 0 & 0 & 0 & 1 & 0 & 0 & 0 \\
\hline $\begin{array}{c}\text { TLS } \\
\text { tarama2 }\end{array}$ & $\begin{array}{c}-23.217 \\
( \pm 0.0685)\end{array}$ & $\begin{array}{c}-14.792 \\
( \pm 0.0341)\end{array}$ & $\begin{array}{c}-0.667 \\
( \pm 0.1226)\end{array}$ & 1 & $\begin{array}{c}0.869 \\
( \pm 0.2571)\end{array}$ & $\begin{array}{c}1.073 \\
( \pm 0.5158)\end{array}$ & $\begin{array}{c}8.421 \\
( \pm 0.1569)\end{array}$ \\
\hline $\begin{array}{c}\text { TLS } \\
\text { tarama3 }\end{array}$ & $\begin{array}{c}69.639 \\
( \pm 0.0661)\end{array}$ & $\begin{array}{c}92.565 \\
( \pm 0.0646)\end{array}$ & $\begin{array}{c}1.284 \\
( \pm 0.7231)\end{array}$ & 1 & $\begin{array}{c}0.681 \\
( \pm 0.4161)\end{array}$ & $\begin{array}{c}0.824 \\
( \pm 0.5422)\end{array}$ & $\begin{array}{c}121.411 \\
( \pm 0.1071)\end{array}$ \\
\hline $\begin{array}{c}\text { TLS } \\
\text { tarama4 }\end{array}$ & $\begin{array}{c}-41.787 \\
( \pm 0.0983)\end{array}$ & $\begin{array}{c}91.305 \\
( \pm 0.0724)\end{array}$ & $\begin{array}{c}-0.751 \\
( \pm 0.3747)\end{array}$ & 1 & $\begin{array}{c}-0.803 \\
( \pm 0.4175)\end{array}$ & $\begin{array}{c}0.009 \\
( \pm 0.2541)\end{array}$ & $\begin{array}{l}-145.441 \\
( \pm 0.1263)\end{array}$ \\
\hline PRD & $\begin{array}{c}5.461 \\
( \pm 0.0722)\end{array}$ & $\begin{array}{c}1.635 \\
( \pm 0.0393)\end{array}$ & $\begin{array}{c}37.384 \\
( \pm 0.0336)\end{array}$ & $\begin{array}{c}0.998 \\
( \pm 0.0006)\end{array}$ & $\begin{array}{c}31.338 \\
( \pm 0.8272)\end{array}$ & $\begin{array}{c}-74.372 \\
( \pm 0.1408)\end{array}$ & $\begin{array}{c}91.914 \\
( \pm 0.7643)\end{array}$ \\
\hline
\end{tabular}




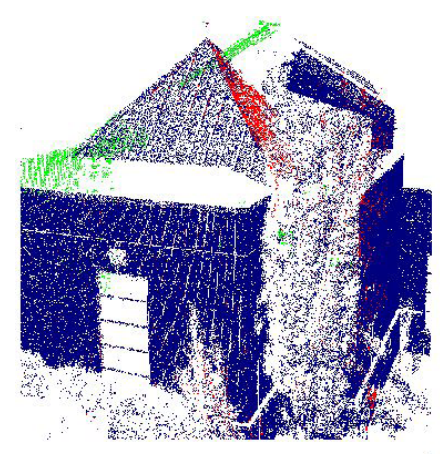

(a)

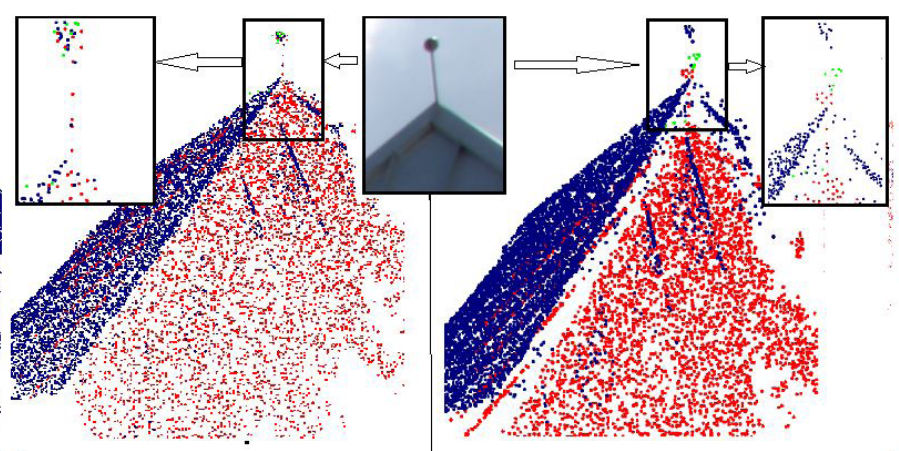

(b)

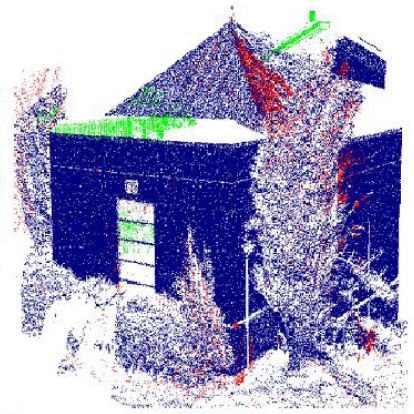

Şekil 2: Düzlemsel özellik tabanlı (a) ve doğrusal özellik tabanlı (b) yaklaşımlar kullanılarak referanslanmış taramalar

olarak görülmektedir. Binanın çatısındaki paratonere karşılık gelen yakınlaştırılmış görüntüyü inceleyiniz. Şekil 2a' da üç tarama uygun şekilde çakışırken Şekil 2b' de ise $Z$ yönünde çakışma hatası görülmektedir. Bu tür çakışma hatası $\mathrm{Z}$ yönündeki hatalı olarak belirlenen yer değiştirmeyle veya doğrusal özellik tabanlı referanslamadan elde edilen taramaları ilişkilendiren $\Omega$ ve $\Phi$ açıları ile ilgilidir. Bu gözlem Tablo 2' deki büyük standart sapma değerleriyle uyumludur (Bu tablodaki vurgulanan hücreleri inceleyiniz).

Nicel kalite kontrolü PRD ve TLS taramaları arasındaki düzlemler için nokta-düzlem normali mesafelerinin hesaplanmasıyla gerçekleştirilmiştir (referanslama aşamasından sonra fotogrametrik veri ve TLS verisinin uyumluluğunu nicel olarak göstererek). PRD ve TLS taramaları belirlenen dönüşüm parametreleri kullanılarak referans koordinat sistemine dönüştürülmüştür. İlk nicel kalite kontrolü olan nokta-düzlem normali mesafesinin belirlemesi yöntemi için, düzlem parametreleri PRD' den hesaplanmıştır ve bölümlenmiş TLS taramalarındaki her bir noktadan PRD düzlemine olan normal mesafeler be-

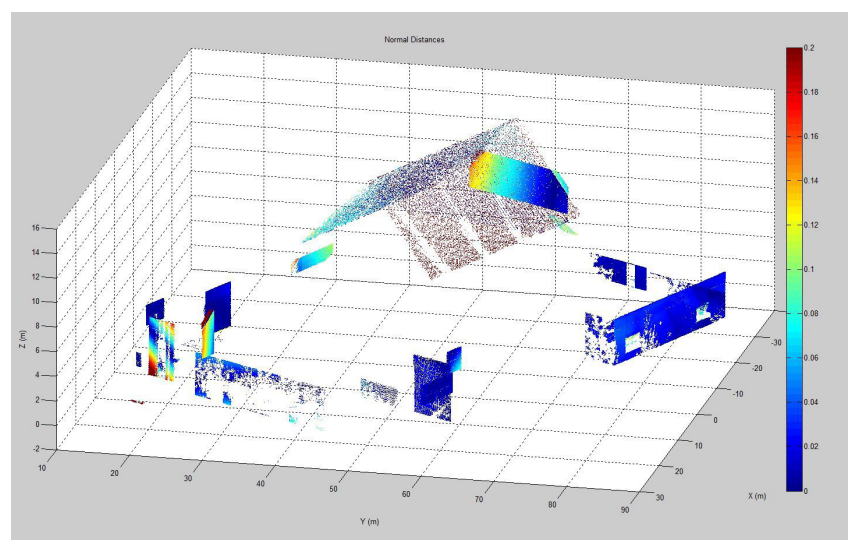

Şekil 3: Doğrusal özellik tabanlı referanslama yöntemi ile elde edilen nokta-düzlem normali mesafeleri (normal mesafelere dayanan renkler sağdaki ölçek çubuğunda görülmektedir) lirlenmiştir. Son olarak, hesaplanan nokta-düzlem normali mesafeleri görsel olarak Şekil 3 ve 4' te gösterilmiştir. Düzlemsel özellik tabanlı referanslama için ortalama normal mesafe 10 cm seviyesinde olmaktadır. Diğer bir yandan, doğrusal özellik tabanlı referanslamada, yatay ve eğimli düzlem özelliklerinde 20 cm' ye kadar ortalama normal mesafe olmaktadır (Şekil 3' deki bina çatıları). Bu düzlemlerin, belirlenen ZT ötelemesinin kalitesi ile beraber farklı taramalar arasındaki $\Omega$ ve $\Phi$ dönüklük açılarının kalitesini doğrulayan düzlemler olduğu unutulmamalıdır. Bir kez daha belirtmek gerekirse, bu parametreler Tablo 2'de degörüleceği üzere yüksek standart sapma değerine sahip parametrelerdir. Bu problemin nedeni bir sonraki paragrafta açıklanacaktır. İkinci nicel kalite kontrol yöntemi olarak önerilen referanslama yönteminden elde edilen sonuçlar ile ICPP' den elde edilen sonuçlar Tablo 3' de karşılaştırılmış, farklı yaklaşımlardan elde edilen büyük farklar sarı renk ile vurgulanmıştır. Tekrarlamak gerekirse, en büyük sapmayı gösteren parametreler ZT ötelemesi ve doğrusal özellik tabanlı referanslamadaki $\Omega$ ve $\Phi$ dönüklük açılarıdır.

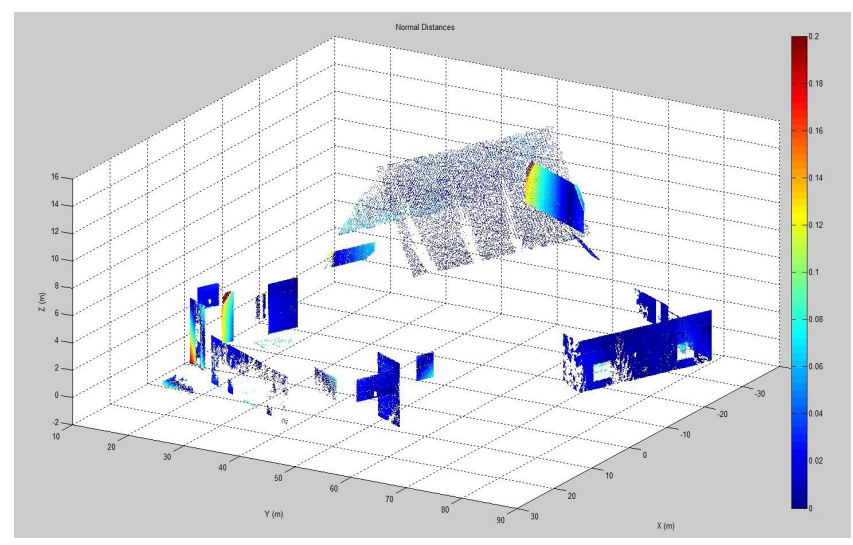

Şekil 3: Düzlemsel özellik tabanlı referanslama yöntemi ile elde edilen nokta-düzlem normali mesafeleri (normal mesafelere dayanan renkler sağdaki ölçek çubuğunda görülmektedir) 
Tablo 3: Önerilen yöntem ile ICPP'den elde edilen sonuçların karşılaştırılması

\begin{tabular}{|c|c|c|c|c|c|c|c|}
\hline & $\begin{array}{l}\text { Referanslama } \\
\text { Parametreleri }\end{array}$ & $\begin{array}{c}\text { ICPP } \\
\text { Yöntemi }\end{array}$ & $\begin{array}{c}\text { Düzlemsel özellik } \\
\text { tabanlı yöntem }\end{array}$ & $\begin{array}{c}\text { Doğrusal özellik } \\
\text { tabanll yöntem }\end{array}$ & $\begin{array}{l}\text { ICPP'ye karssl } \\
\text { düzlemsel özellik } \\
\text { tabanll yöntemler }\end{array}$ & $\begin{array}{c}\text { ICPP'ye karssl } \\
\text { doğrusal özellik } \\
\text { tabanll yöntemler }\end{array}$ & $\begin{array}{c}\text { Doğrusal'a } \\
\text { Därşl } \\
\text { Düzlemsel }\end{array}$ \\
\hline \multirow{7}{*}{ TLS tarama 2} & XT (m) & -23.258 & -23.186 & -23.217 & -0.072 & -0.041 & 0.031 \\
\hline & YT (m) & -14.733 & -14.801 & -14.792 & 0.067 & 0.058 & -0.009 \\
\hline & ZT (m) & -0.605 & -0.687 & -0.667 & 0.082 & 0.062 & -0.020 \\
\hline & Scale & 1 & 1 & 1 & 0 & 0 & 0 \\
\hline & $\Omega\left({ }^{\circ}\right)$ & 0.177 & 0.234 & 0.869 & -0.056 & -0.691 & -0.635 \\
\hline & $\phi\left({ }^{\circ}\right)$ & -0.189 & -0.429 & 1.073 & 0.239 & -1.262 & -1.502 \\
\hline & $K\left({ }^{\circ}\right)$ & 8.168 & 8.373 & 8.421 & -0.204 & -0.252 & -0.048 \\
\hline \multirow{7}{*}{ TLS tarama 3} & XT (m) & 69.613 & 69.677 & 69.639 & -0.063 & -0.025 & 0.038 \\
\hline & YT (m) & 92.579 & 92.511 & 92.565 & 0.068 & 0.014 & -0.054 \\
\hline & ZT (m) & 1.375 & 1.335 & 1.284 & 0.040 & 0.091 & 0.051 \\
\hline & Scale & 1 & 1 & 1 & 0 & 0 & 0 \\
\hline & $\Omega\left({ }^{0}\right)$ & 0.095 & 0.243 & 0.681 & -0.147 & -0.585 & -0.438 \\
\hline & $\phi\left({ }^{\circ}\right)$ & 0.194 & 0.313 & 0.824 & -0.118 & -0.629 & -0.511 \\
\hline & $K\left({ }^{0}\right)$ & 121.388 & 121.373 & 121.411 & 0.015 & -0.022 & -0.038 \\
\hline \multirow{7}{*}{ TLS tarama 4} & XT (m) & -41.751 & -41.693 & -41.787 & -0.057 & 0.036 & 0.094 \\
\hline & YT (m) & 91.313 & 91.37 & 91.305 & -0.056 & 0.008 & 0.065 \\
\hline & ZT (m) & -0.259 & -0.251 & -0.751 & -0.008 & 0.491 & 0.500 \\
\hline & Scale & 1 & 1 & 1 & 0 & 0 & 0 \\
\hline & $\mathbf{\Omega ( { } ^ { \circ } )}$ & -0.204 & -0.291 & -0.803 & 0.086 & 0.598 & 0.512 \\
\hline & $\phi\left({ }^{\circ}\right)$ & 0.002 & 0.165 & 0.009 & -0.162 & -0.006 & 0.156 \\
\hline & $K\left({ }^{\circ}\right)$ & -145.53 & -145.531 & -145.441 & -0.007 & -0.097 & -0.09 \\
\hline \multirow{7}{*}{$P R D$} & XT (m) & - & 5.372 & 5.461 & - & - & -0.089 \\
\hline & YT (m) & - & 1.611 & 1.635 & - & - & -0.025 \\
\hline & ZT (m) & - & 37.383 & 37.384 & - & - & -0.001 \\
\hline & Scale & - & 0.998 & 0.998 & - & - & 0 \\
\hline & $\Omega\left({ }^{\circ}\right)$ & - & 30.584 & 31.338 & - & - & -0.754 \\
\hline & $\phi\left({ }^{\circ}\right)$ & - & -74.546 & -74.372 & - & - & -0.174 \\
\hline & $K\left({ }^{0}\right)$ & - & 91.168 & 91.914 & - & - & -0.746 \\
\hline
\end{tabular}

Doğrusal özellik tabanlı referanslama probleminin daha detay- karşılık gelmeyebilir. Şekil 5' de bu tip bir probleme örnek 11 incelenmesi Şekil 2 ve 3 ile Tablo 2 ve 3' deki anormalliklerin nedenini açığa çıkarmaktadır. Daha önce de bahsedildiği üzere, referanslama yaklaşımında fotogrametrik veri ve TLS taramalarından türetilen özdelliklerin eşlenik olduğu varsay11ır. Bu varsayım düzlemsel özellikler için geçerli iken doğrusal özellikler için geçerli olmak zorunda değildir. Daha da detaya inersek, TLS taramalarından çıkarılan doğrusal özellikler fotogrametrik veride tanımlanan fiziki doğrusal özelliklere gösterilmiştir. $\mathrm{Bu}$ çeşit bir problem genellikle eğimli veya yatay doğrusal özelliklerin çokça yer aldığı çatı kısımlarında görülmektedir.

PRD ve TLS taramalarındaki birbirine karşılık gelmeyen eğimli veya yatay doğrusal özellikler $Z T, \Omega$ ve $\Phi$ değerlerinin yanlış belirlenmesinde temel nedendir. Çünkü, bu özellikler en küçük kareler dengeleme yönteminde ZT, $\Omega$ ve $\Phi$ parametrelerinin belirlenmesinde katkı sağlamaktadır.
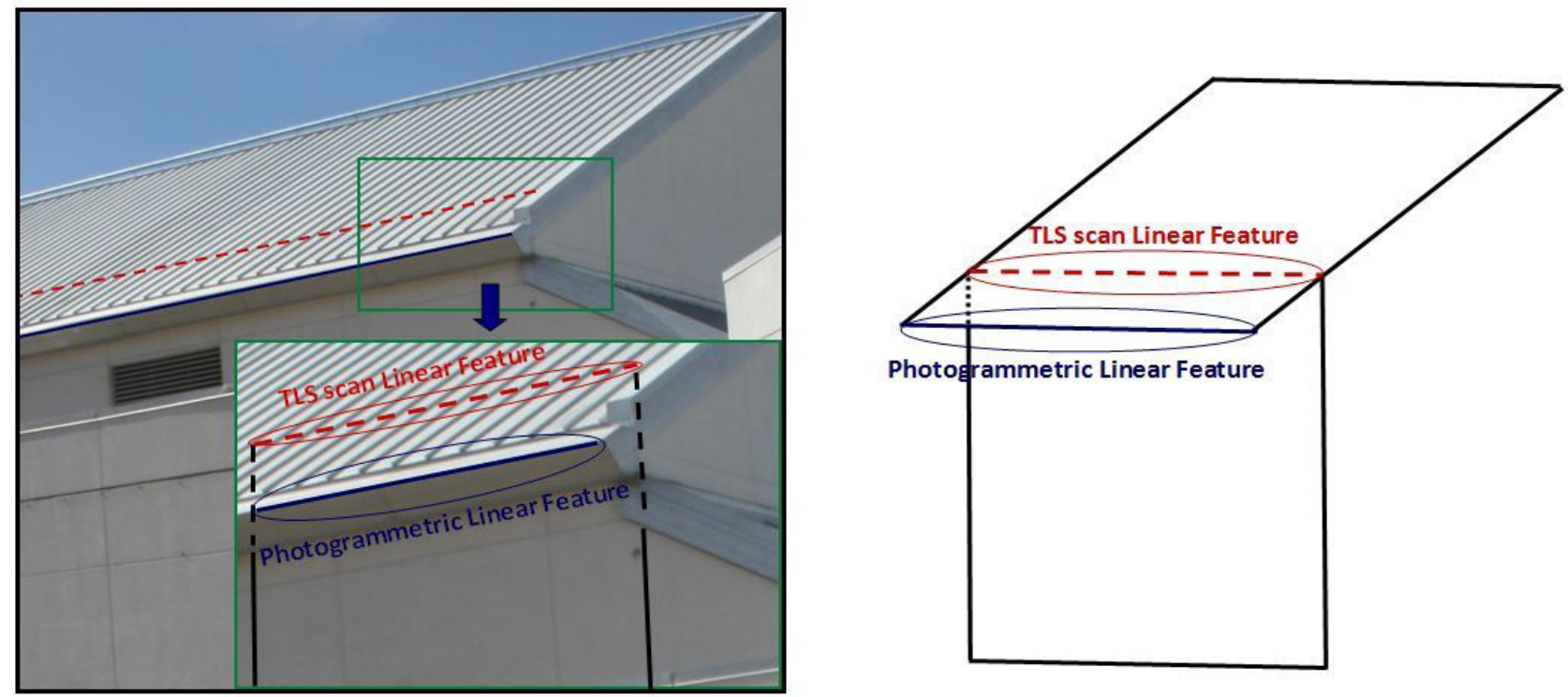

Șekil 5: Doğrusal özellik tabanlı referanslama yaklaşımı ile ilgili bir problem (Fotogrametrik verideki tanımlanabilir doğrusal özelliklere karşılık gelmeyen TLS dogrusal özellikleri 


\section{Sonuçlar ve gelecek çalışmalar için öneriler}

$\mathrm{Bu}$ çalışmada çakıştırılmış TLS taramaları için yeni bir referanslama yöntemi önerilmiştir. ICP ve türevleri gibi sıklıkla kullanılan referanslama yöntemleri minimum bindirmeli TLS taramalarını referanslandırmada başarısız olmaktadırlar. Önerilen yöntem hızlı ve ekonomik şekilde elde edilebilen, ilgili nesneyi kaplayan fotogrametrik veriler kullanılarak referanslamada başarılı olmuştur. Önerilen yöntem farklı taramaları ilişkilendiren dönüşüm parametrelerinin belirlenmesi için fotogrametrik veri ve TLS verilerinden çıkarılan doğrusal veya düzlemsel özellikler kullanır. Karşılıklı doğrusal ve düzlemsel özellikleri temsil etmek için eşlenik olmayan noktalar kullanılmasına rağmen, eşlenik olmayan noktaların kullanımından kaynaklanan sistematik bileşeni yok etmek ve TLS taramaları ve fotogrametrik verilerde karşılıklı özellikler arasındaki normal mesafeleri en aza indirmek için gözlem denklemlerindeki rastgele hataların ağırlıklarını değiştirdikten sonra, nokta tabanlı bir benzerlik ölçümü kullanılmıştır.

Önerilen yaklaşımın performansını doğrulamak için referanslanmış taramaların nitel görselleştirilmesi gerçekleştirilmiştir. Buna ek olarak, önerilen referanslama yönteminin performansını değerlendirmek için nicel kalite kontrol ölçümleri ortaya konulmuştur. İlk olarak, referanslanmış yüzeyler arasındaki nokta-düzlem normali mesafeleri hesaplanmıştır. İkinci olarak, alt modeller arasındaki bindirmeyi arttırmak için daha fazla tarama ekledikten sonra, önerilen yöntemden elde edilen sonuçlar ile ICPP yönteminden elde edilen sonuçlar nicel olarak karşılaştırılmıştır. Kalite kontrol analizlerine göre düzlemsel özellik tabanlı referanslama yöntemi doğrusal özellik tabanlı referanslama yöntemine göre daha güvenilir sonuçlar vermektedir. Doğrusal özelliklerin düşük doğrulukta sonuç vermelerinin nedeni TLS verisinden çıkarılan doğrusal özelliklerin fotogrametrik veride tanımlanabilen fiziki doğrusal özelliklere karşılık gelmemesidir. Mevcut ve gelecekteki çalışmalar fotogrametrik veriden referanslama kontrol detaylarının otomatik çıkarılmasına yönelik olacaktır. Buna ek olarak, fotogrametrik verideki ve TLS verisindeki eşlenik özelliklerin tanımlanması ele alınacaktır.

\section{Teşekkür}

Bu makale Kanada Fen Bilimleri ve Mühendislik Araştırma Konseyi ve TECTERRA' nın ekonomik desteği ile gerçekleştirilmiştir. Ayrıca, Calgary Üniversitesi' nin Dijital Fotogrametri Araştırma Grubu üyelerinin fotogrametrik ve lazer tarama verisi elde etmedeki yardımlarından dolayı teşekkürü borç biliriz.

\section{Kaynaklar}

Al-Durgham M. (2007), Alternative Methodologies for the Quality Control of LiDAR Systems. Yüksek Lisans Tezi, Department of Geomatics Engineering, University of Calgary, Kanada, ss. 66-68.

Al-Durgham M., Detchev I., Habib A., (2011), Analysis of Two Triangle-Based Multi-Surface Registration Algorithms of Irregular Point Clouds, ISPRS Workshop Laser Scanning 2011, XXXVIII-5/W12, Calgary, Kanada, 29-31 Ağustos, 2011.
Al-Manasir K., Fraser C. S., (2006), Automatic Registration of Terrestrial Laser Scanner Data via Imagery. The International Archives of the Photogrammetry Remote Sensing and Spatial Information Sciences(IAPRS), Dresden 25-27 Eylül, 35(5), ss. 26-31.

Al-Ruzouq R., (2004), Semi-Automatic Registration of Multi-Source Satellite Imagery with Varying Geometric Resolutions, Doktora Tezi, Department of Geomatics Engineering, University of Calgary, Kanada, ss.10-24.

Balzani M., Pellegrinelli A., Perfetti N., Russo P., Uccelli F., Tralli S., (2002), Cyrax ${ }^{\mathrm{TM}} 2500$ laser scanner and G.P.S. operational flexibility: from detailed close range surveying, to urbanscale surveying. Proceedings of International Workshop on Scanning for Cultural Heritage Recording - Complementing or Replacing Photogrammetry' nin içinde, Corfu, Yunanistan, 1 - 2 Eylül.

Besl P. J., McKay N. D., (1992), A method for registration of 3-D shapes, IEEE Transactions on Pattern Analysis and Machine Intelligence, 14(2), ss. 239-256, doi: 10.1109/34.121791.

Chen Y., Medioni G., (1992), Object modeling by registration of multiple range images, Image and Vision Computing 10(3), ss. 145-155, doi: 10.1016/0262-8856(92)90066-C.

Dold C., Brenner C., (2006), Registration of Terrestrial Laser Scanning Data Using Planar Patches and Image Data, IAPRS Volume XXXVI, Part 5, Dresden 25-27 Eylül 2006.

Habib A., Ghanma M. S., Tait M., (2004), Integration of LIDAR and Photogrammetry for Close Range Applications, XXth ISPRS Congress: Proceedings of Commission V, 7 Temmuz 2004, Türkiye.

Habib A., Bang K. I., Aldelgawy M., Shin S. W., Kim K. O., (2007), Integration of Photogrammetric and LIDAR Data in a MultiPrimitive Triangulation Procedure, Conf. American Society Photogrammetry Remote Sensing Conference, Tampa, Florida, May1s 7-11 2007.

Habib A., Kersting A. P., Ruifanga Z., Al-Durgham M., Kim C., and Lee D. C., (2008), Lidar Strip Adjustment Using Conjugate Linear Features in Overlapping Stripts, The International Archives of the Photogrammetry, Remote Sensing and Spatial Information Sciences, XXXVII. Part B1, Beijing 2008, ss. 386-390.

Habib A., Kwak E., Al-Durgham M., (2011), Model-Based Automatic 3D Building Model Generation by Integrating LiDAR and Aerial Images, Archives of Photogrammetry, Cartography and Remote Sensing, 22, ss. 187-200

Kersting A. P. B., (2012), Quality Assurance of Multi-Sensor Systems, Doktora Tezi, Department of Geomatics Engineering, University of Calgary, Kanada, ss. 15-160.

Lari Z., Habib A., Kwak E., (2011), An Adaptive Approach for Segmentation of $3 D$ Laser Point Cloud, ISPRS Workshop Laser Scanning 2011, Calgary, Kanada, 29 - 31 Ağustos 2011.

Lari Z., Habib A., (2012), A new approach for segmentation of multi-resolution and multi-platform LiDAR data, Proceedings of Global Geospatial Conference, Québec City, Kanada, 14-17 May1s 2012.

Renaudin E., Habib A., and Kersting A. P., (2011), Featured-Based Registration of Terrestrial Laser Scans with Minimum Overlap Using Photogrammetric Data. ETRI Journal, 33(4), ss. 517527, doi: 10.4218/etrij.11.1610.0006. 